\title{
Artificial Intelligence Model based on Grey Clustering for Integral Analysis of Industrial Hygiene Risk
}

\author{
Alexi Delgado ${ }^{1}$, Diana Aliaga ${ }^{2}$, Cristian Carlos $^{3}$, Lisseth Vergaray ${ }^{4}$, Chiara Carbajal $^{5}$ \\ Mining Engineering Section, Pontificia Universidad Católica del Perú, Lima, Peru ${ }^{1}$ \\ Faculty of Environmental Engineering, Universidad Nacional de Ingeniería, Lima, Peru ${ }^{2,3,4}$ \\ Administration Program, Universidad de Ciencias y Humanidades, Lima, Perú
}

\begin{abstract}
The article proposes a model with an artificial intelligence approach that integrates risks through the Grey Clustering method applying the "Triangulation of center-point based on Whitening functions -CTWF", for this, the data established is standard data (minimum standards that the four workshops of a company in the industrial sector must meet) and sampled data (real data obtained in the field) to test the grey classes. In this study, the different types of risks (lighting, noise and hand-arm vibration) were globally evaluated and analyzed in the four workshops of a heavy machinery maintenance services company in the industrial sector (welding shop, hydraulic shop, machine shop 1 and machine shop 2), located in Lima, Peru. According to the results obtained from the level of hygienic quality in each workshop, the welding workshop is at a very poor-quality level, while the others are at a good and very good level; regarding the four workshops, it was determined that the noise level is not recommended as they do not meet the minimum required standards. Therefore, control measures were proposed in the four workshops where the level of irrigation is bad and very bad. This study will benefit companies in the industrial sector that need to analyze the level of hygienic quality in their work areas with a global approach in order to apply control measures with prevention, protection of health and physical integrity of workers.
\end{abstract}

Keywords-Artificial intelligence; grey clustering; industrial hygiene; lighting; noise

\section{INTRODUCTION}

Actually in the companies of the industrial sector, there can be found diverse types of risks that can affect the zone of comfort and the health of the workers such as excessive level of noise, inadequate illumination, high levels of vibration, etc. [1]; where generally does not exist a method that simultaneously covers these types of risks that will be necessary to obtain indicators of management of safety and occupational health. Therefore the present study proposes a model based on artificial intelligence that integrates these risks through the method of Grey Clustering [2] applied in an industrial sector company located in Lima - Peru, where it is detected that in some of its workshops there are high levels of exposure to hygiene risks such as noise, lighting and vibration; being necessary to have an objective assessment and also propose control measures that is where this study aims.
In this study, risk levels will be evaluated in four workshops of a heavy machinery maintenance service company of the industrial sector (welding workshop, hydraulic workshop, machine workshop 1 and machine workshop 2), located in the province of Lima, Peru, where the results obtained in the occupational hygiene monitoring are observed as high levels of noise, lighting and hand-arm vibration, which will be evaluated globally in each workshop through the Grey Clustering method [3].

In the present study, it is proposed to use the Grey Clustering methodology, which is an artificial intelligence approach [4], to be applied by means of "Centrepoint Triangulation based on Whitenization Functions - CTWF" [5], since these are mainly applied to test if the objects of observation belong to predetermined classes, known as grey classes [6], as it is evidenced in the studies of selection of innovative strategies [7], in the evaluation of air quality by grey incidence [8], as well as in the management of occupational safety and health [9]; and as this study will be based on a small group of criteria with limited information, its application will be the most appropriate as grey clustering Method considers this in its analysis.

For this reason, the specific objective of this study is to simultaneously analyze the different types of risks (lighting, noise and hand-arm vibration) present in each workshop, where a global evaluation of the risks will be obtained according to the methodology of Grey Clustering [10] in the heavy machinery maintenance service company of the industrial sector in Peru, and based on the application of the method, control measures can be proposed.

This study is organized as follows: The introduction is presented in Section I. Section II describes the literature review. The methodology is provided in detail in Section III, the case study is described in Section IV; followed by the results and discussions in Section V, and finally in Section VI the conclusions are mentioned.

\section{LITERATURE REVIEW}

In the study "Evaluation of the noise risk level and its consequences for the technical operators of tobacco processing equipment in a cigarette producing company in Nigeria" the noise generated by machines in three tobacco companies was evaluated and analyzed. Therefore, it was found that all 
technical operators are exposed to intense noise above $85 \mathrm{~dB}$, likewise, in the analysis carried out it was shown that all companies operated with efficiencies lower than 55\% [11].

In the study "Hearing Loss of Workers Exposed to Noise in a Metalworking Company" the prevalence of hearing loss was determined in 164 workers exposed to noise at levels of 83 to $102 \mathrm{~dB}$, there were analyzed variables such as age, seniority in the job, the use of personal protective equipment and blows to the head, were also included the results of the audiometry made to the workers and the result of the monitoring of noise levels in the work areas. The study determined that $53 \%$ of the workers showed normal hearing, while $47 \%$ had hearing loss [12].

The objective of the study "Evaluation of lighting levels in interiors and calculation for lighting installations" is to evaluate the level of lighting that the construction workers are exposed to within the workshops of the oil area where the hygienic assessment of physical risk was applied of the Normal Official Mexican. Regarding the lighting conditions in the work centers, the value obtained is compared with what is established in the standards of Executive Decree 2393, where for the calculation of general lighting in interior facilities, the method called General System or the Utilization factor provided average luminance. Likewise, the average evaluation result was 458.22 luxes, which is below the permissible minimum of 500 luxes for design work, revision and correction of plans, so that intervention is necessary through a program to prevent physical risks from lighting [13].

In the study "Response to vibration of the human arm in machine operation", it was carried out in a worker exposed to the vibrations of heavy machines in the industry to determine the risk of musculoskeletal disorders. To examine the effect of these alterations, it was created a 3D model of the human arm in SolidWorks followed by an analysis in ANSYS to obtain the response of the human arm. The analytical and experimental study showed that the degradation of the internal human structure is exponential due to the continuous vibrations that the human body experiences and increases the probability of musculoskeletal disorders [14].

In the study "Evaluation of exposure to vibration risk in the hand-arm segment in companies of the metal-mechanic sector", the accelerations caused by vibrating tools such as: polishers, grinders, drills, among others, were measured and compared with the permissible exposure registered in ISO 5349 of 2002 for the hand-arm-body segment. The study was carried out in four companies of the metal-mechanic sector in the city of Cali. The components studied associated with vibrations were: acceleration, velocity and amplitude. The study showed that the evaluations performed on 15 types of tools did not exceed the permissible limits established by the American Government of Industrial Hygienists of the United States ACGIH 2014, which corresponds to $2.8 \mathrm{~m} / \mathrm{s}^{2}[15]$.

\section{Methodology}

The Grey Clustering method is based on the theory of grey systems. Grey systems study problems with small samples and limited information, where there are currently several problems of this type [6], this fact makes that grey systems can be applied in different fields, one of them would be in the field of industrial hygiene and safety, since its study in the evaluation of occupational agents usually has this characteristic, in addition this method was applied in different areas such as water management [16], environmental conflicts [17] and the management of occupational safety [9].

The Grey Clustering method was developed to classify observation indices or observation objects into categories using Grey incidence matrices or whitening weighting functions [18]. The method is mainly applied to test whether observation groups belong to predetermined categories.

The present study will use the Grey Clustering method based on central point whitenization triangular functions (CTWF) [9]. For that, we have a set of groups " $m$ ", and a set of criteria " $n$ " and a set of different grey classes " $s$ ", according to the sample $x_{i j}(i=1,2, \ldots m ; j=1,2, \ldots \ldots n)$ and we have as groups $(i=1,2,3 \ldots m)$ and for the criteria $(j=1,2,3 \ldots n)$. The CTWF-based grouping of grey classes can be expressed as follows [19], [20]:

Step 1: The individual ranges of the criteria are divided into $" s "$ Grey classes, to then determine the central points of each range in: $\lambda_{1}, \lambda_{2}, \ldots, \lambda_{s}$ of Grey classes $1,2, \ldots, s$ of the standard data.

Step 2: Non-dimension of the standard data of each study $\operatorname{object}(i)$ and of the selected criteria $(j)$ is carried out. First, the average of the central point's $\lambda_{1}, \lambda_{2}, \ldots, \lambda_{s}$ found with step 1 is taken, then each central point will be divided by the mean for each criterion with (1).

$\lambda_{j}^{k}=\frac{\lambda_{k}}{\frac{1}{s} \sum_{k=1}^{S} \lambda_{k}}$

Step 3: The Grey classes are extended in two directions, adding the Grey classes 0 and $(s+1)$ with their center points $\lambda_{0}$ and $\lambda_{s+1}$ respectively. Therefore, the new sequence of central points is set $\lambda_{0}, \lambda_{1}, \lambda_{2}, \ldots, \lambda_{s}, \lambda_{s+1}$ (see Fig. 1). Therefore, the CTWF for the class Grey $k^{t h}, k=1,2, \ldots, s$, of the criterion $j^{\text {th }}, j=1,2, \ldots, n$, for an observed value $x_{i j}$ is defined by (2).

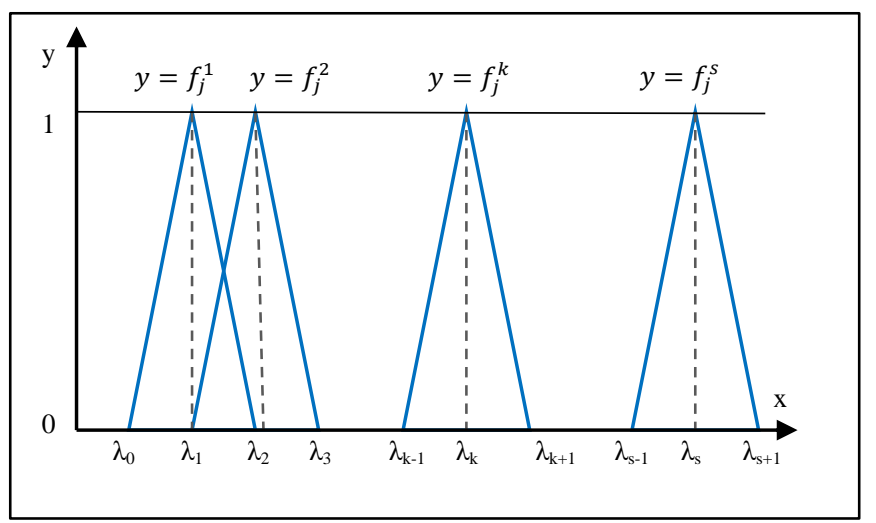

Fig. 1. Center-Point based on Whitening Functions - CTWF [20]. 
$f_{j}^{k}=\left\{\begin{array}{c}0 ; x \notin\left[\lambda_{0}, \lambda_{1}\right] \\ \frac{x-\lambda_{k-1}}{\lambda_{k}-\lambda_{k-1}} ; x \in\left[\lambda_{k-1}, \lambda_{k}\right] \\ \frac{\lambda_{k-1}-x}{\lambda_{k+1}-\lambda_{k}} ; x \in\left[\lambda_{k}, \lambda_{k+1}\right]\end{array}\right.$

Where: is the CFW of the $k^{\text {th }}$ Grey class of the $j^{\text {th }}$ criterion and is the weight of the $j$ criterion.

Step 4: The weights of the criteria are calculated using the harmonic mean, first the inverse of the dimensionless or nondimension standard data must be determined and divided by the sum of the inverses found, it will be calculated using (3).

$n_{j}^{k}=\frac{\frac{1}{\lambda_{j}^{k}}}{\sum_{j=1}^{m} \frac{1}{\lambda_{j}^{k}}}$

Step 5: The Clustering coefficient $\sigma_{i}^{k}$, which indicates the weight of the criteria, for group $i, i=1,2, \ldots, m$, with respect to the Grey class $k, k=1,2, \ldots, s$ is calculated by (4).

$\sigma_{i}^{k}=\sum_{j=1}^{n} f_{j}^{k}\left(x_{i j}\right) \cdot n_{j}$

Step 6: If $\max _{1 \leq k \leq s}\left\{\sigma_{i}^{k}\right\}=\sigma_{i}^{k^{*}}$, we decide that the object belongs to the class Grey $k^{*}$. However, when there are several objects in the Grey class $k^{*}$, these objects can be ordered according to the magnitudes of their Clustering coefficients and we stretch the result for each object of study.

\section{CAse Study}

The application of the method will be carried out in 4 areas of a company of maintenance services of heavy machinery, considering three parameters (Noise, Lighting and vibration) for the analysis of the conditions of industrial hygiene, the company is located in the industrial avenue, Cercado de Lima Peru.

Fig. 2 shows the location of Peru and Lima region where the study was conducted.

In Fig. 3, the locations of the four study areas within the industrial plant are shown.

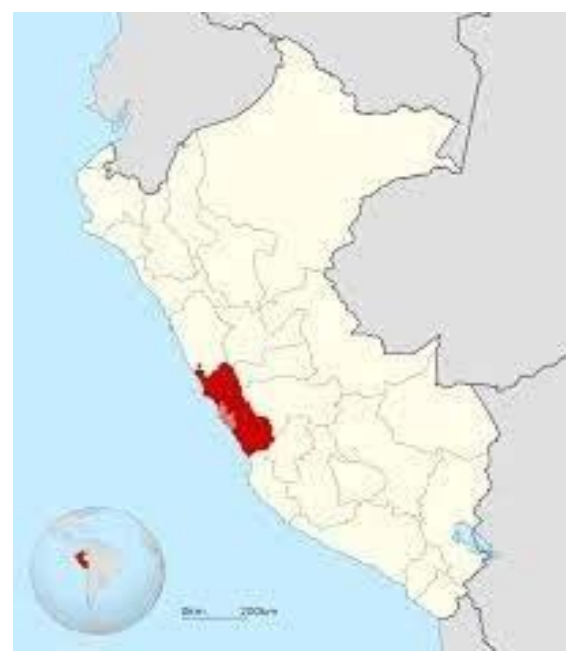

Fig. 2. Location of Peru and the Lima Region.

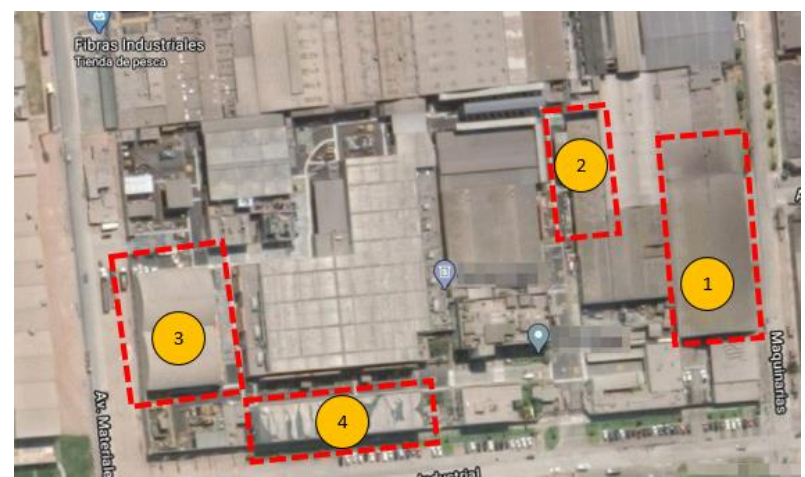

Fig. 3. Location of the Workshops to be Analyzed: (1) Welding Workshop, (2) Hydraulic Workshop, (3) Machine Workshop 1 and (4) Machine Workshop 2. Source: Google Maps.

\section{A. Definition of Study Objects}

The study will be based on the data obtained from the monitoring reports of occupational hygiene in four workshops of a heavy machinery maintenance service company. In Table I, the objects are defined by assigning them an abbreviated notation.

TABLE I. STUdy OBJeCts' NotATIONS

\begin{tabular}{|l|l|}
\hline Objects & Notation \\
\hline Welding workshop & G1 \\
\hline Hydraulic Workshop & G2 \\
\hline Machine Workshop 1 & G3 \\
\hline Machine Workshop 2 & G4 \\
\hline
\end{tabular}

\section{B. Definition of Evaluation Criteria}

The criteria for this study are defined in Table II.

In Table III, the average data of the criteria obtained from the reports of occupational hygiene realized in the month of September and October 2019 is presented, whose values are projected for a working day of 8 hours.

\section{Definition of Grey Classes}

In Table IV, the grey classes that have been defined in four ranges and will represent the levels of hygienic quality in the different objects of studies mentioned in the Table I.

TABLE II. CRITERIA WITH THEIR RESPECTIVE UNIT AND NOTATION

\begin{tabular}{|l|l|l|}
\hline Criteria & Unit & Notation \\
\hline Noise & Decibel & $\mathrm{C} 1$ \\
\hline Illumination & Lux & $\mathrm{C} 2$ \\
\hline Vibration & $\mathrm{m} / \mathrm{s} 2$ & $\mathrm{C} 3$ \\
\hline
\end{tabular}

TABLE III. AVERAGE VALUES OF THE CRITERIA OBTAINED FROM THE OCCUPATIONAL HYGIENE REPORTS OF THE WORKSHOPS

\begin{tabular}{|l|l|l|l|}
\hline Objects & C1 (dB) & C2 (Lux) & C3 (m/s2) \\
\hline G1 & 98.18 & 615.20 & 4.196 \\
\hline G2 & 91.18 & 463.73 & 1.783 \\
\hline G3 & 96.40 & 649.72 & 1.750 \\
\hline G4 & 97.40 & 1131.75 & 1.085 \\
\hline
\end{tabular}


TABLE IV. GREY ClASSES’ NOTATIONS

\begin{tabular}{|l|l|}
\hline Level & Notation \\
\hline Very poor & $\lambda 1$ \\
\hline Poor & $\lambda 2$ \\
\hline Good & $\lambda 3$ \\
\hline Very good & $\lambda 4$ \\
\hline
\end{tabular}

Also, the ranges of the criteria are divided in 4 Grey classes $\lambda_{1}, \lambda_{2}, \lambda_{3}$ and $\lambda_{4}$, are shown in Table V. To establish the intervals of the grey classes for each criterion, used national standards such as RM No. 375 - 2008 -TR [21], and documents from international organizations such as the Encyclopedia of Occupational Safety and Health in the work of OIT [22].

TABLE V. RANKS OF THE CRITERIA AND THEIR 4 GREY ClASSES

\begin{tabular}{|l|l|l|l|l|}
\hline \multirow{2}{*}{ Criteria } & \multicolumn{3}{|l|}{ Grey Classes } & \multicolumn{2}{l|}{} \\
\cline { 2 - 5 } & Very poor & Poor & Good & Very good \\
\hline C1: Noise & $85-100$ & $70-85$ & $65-70$ & $60-65$ \\
\hline C2: Illumination & $100-300$ & $300-500$ & $500-800$ & $800-1000$ \\
\hline C3: Vibration & $4-6$ & $2.5-4$ & $1-2.5$ & $0-1$ \\
\hline
\end{tabular}

\section{Calculations with Grey Clustering}

Step 1: Determine the center points. The central points are obtained from the semi-sum of the extremes of each range shown in Table V, and these values are shown in Table VI.

TABLE VI. CENTRAL POINTS OF THE CRITERIA FOR EACH GREy Class

\begin{tabular}{|l|l|l|l|l|}
\hline \multirow{2}{*}{ Criteria } & \multicolumn{3}{|l|}{ Grey Classes } & \multicolumn{3}{l|}{} \\
\cline { 2 - 5 } & Very poor & Poor & Good & Very good \\
\hline C1: Noise & 92.5 & 77.5 & 67.5 & 62.5 \\
\hline C2: Illumination & 200 & 400 & 650 & 900 \\
\hline C3: Vibration & 5 & 3.25 & 1.75 & 0.5 \\
\hline
\end{tabular}

Step 2: Non-dimension. Table VII shows the results obtained from the non-dimensioning of the standard data by means of (1).

TABLE VII. DimENSIONLESS VALUES OF STANDARD DATA

\begin{tabular}{|l|l|l|l|l|}
\hline Criteria & \multicolumn{1}{|c|}{$\boldsymbol{f}_{\boldsymbol{j}}^{\mathbf{1}}(\boldsymbol{x})$} & \multicolumn{1}{|c|}{$\boldsymbol{f}_{\boldsymbol{j}}^{\mathbf{2}}(\boldsymbol{x})$} & $\boldsymbol{f}_{\boldsymbol{j}}^{\mathbf{3}}(\boldsymbol{x})$ & \multicolumn{1}{|c|}{$\boldsymbol{f}_{\boldsymbol{j}}^{\mathbf{4}}(\boldsymbol{x})$} \\
\hline C1: Noise & 1.23 & 1.03 & 0.90 & 0.83 \\
\hline C2: Illumination & 0.37 & 0.74 & 1.21 & 1.67 \\
\hline C3: Vibration & 1.90 & 1.24 & 0.67 & 0.19 \\
\hline
\end{tabular}

Table VIII shows the results obtained from the sizing of the sampling data, which is obtained by dividing each data by the mean of the standard data for each criterion.

TABLE VIII. DimENSIONLESS VALUES OF THE SAMPLING DATA

\begin{tabular}{|l|l|l|l|l|}
\hline Criteria & G1 & G2 & G3 & G4 \\
\hline C1: Noise & 1.31 & 1.22 & 1.29 & 1.30 \\
\hline C2: Illumination & 1.14 & 0.86 & 1.21 & 2.11 \\
\hline C3: Vibration & 1.60 & 0.68 & 0.67 & 0.41 \\
\hline
\end{tabular}

Step 3: Determination of triangular functions and values. The whitenization functions are elaborated for each evaluation criterion with the data shown in Table VII, which is the reason three functions are considered (noise, illumination, and vibration). Next, the function for the noise criterion is presented (see Fig. 4).

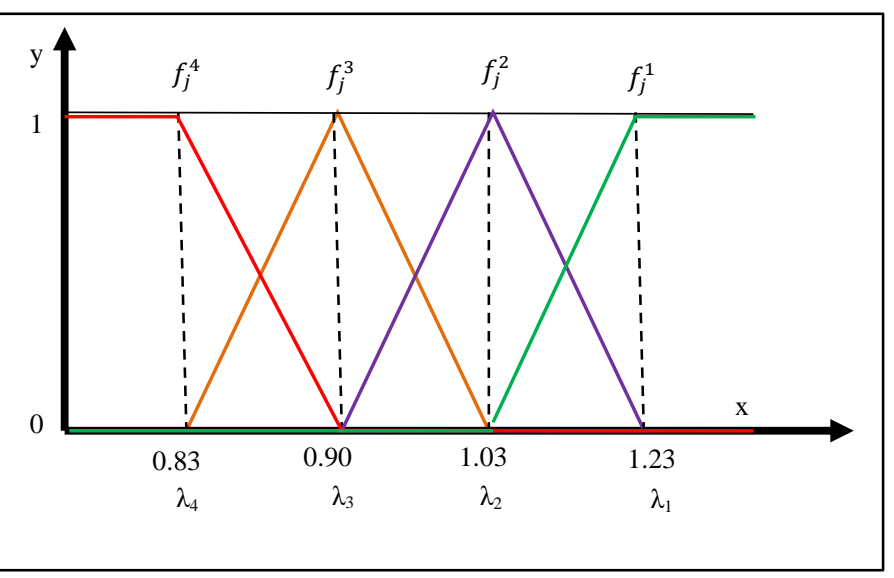

Fig. 4. Whitenization Functions for Criterion 1.

As an example, the functions corresponding to criterion 1 (Noise) are presented in (5) - (8).

$f_{j}^{1}=\left\{\begin{array}{c}1 ; x \in[1.23 ;+\infty\rangle \\ \frac{1.03-x}{1.03-1.23} ; x \in\langle 1.03 ; 1.23\rangle \\ 0 ; x \in[0 ; 1.03]\end{array}\right.$

$f_{j}^{2}=\left\{\begin{array}{l}0 ; x \in[0 ; 0.90] \cup[1.23 ;+\infty\rangle \\ \frac{x-0.90}{1.03-0.90} ; x \in\langle 0.90 ; 1.03] \\ \frac{1.23-x}{1.23-1.03} ; x \in\langle 1.03 ; 1.23\rangle\end{array}\right.$

$f_{j}^{3}=\left\{\begin{array}{l}0 ; x \in[0 ; 0.83] \cup[1.03 ;+\infty\rangle \\ \frac{x-0.83}{0.90-0.83} ; x \in\langle 0.83 ; 0.90\rangle \\ \frac{1.03-x}{1.03-0.90} ; x \in\langle 0.90 ; 1.03\rangle\end{array}\right.$

$f_{j}^{4}=\left\{\begin{array}{c}1 ; x \in[0 ; 0.83\rangle \\ \frac{0.90-x}{0.90-0.83} ; x \in\langle 0.83 ; 0.90\rangle \\ 0 ; x \in[0.90 ;+\infty\rangle\end{array}\right.$

The functions of the other criteria are developed following the same procedure as above.

In Table IX, the results shown in the welding workshop, after evaluating non-dimensioning sampling values (Table VIII) in the functions of each criterion.

TABLE IX. VALUES OF THE FUNCTIONS EVALUATED IN THE WELDING WORKSHOP

\begin{tabular}{|c|l|l|l|}
\hline Criteria & $\mathbf{C 1}$ & $\mathbf{C 2}$ & $\mathbf{C 3}$ \\
\hline$f_{j}^{1}$ & 1.00 & 0.00 & 0.55 \\
\hline$f_{j}^{2}$ & 0.00 & 0.15 & 0.45 \\
\hline$f_{j}^{3}$ & 0.00 & 0.85 & 0.00 \\
\hline$f_{j}^{4}$ & 0.00 & 0.00 & 0.00 \\
\hline
\end{tabular}


Table $\mathrm{X}$ shows the results of the hydraulic workshop, after evaluating the non-dimensioning values of Table VIII in the functions of each criterion.

TABLE X. VALUES OF THE FunCtions Evaluated IN THE Hydraulic WORKSHOP

\begin{tabular}{|c|l|l|l|}
\hline Criteria & C1 & C2 & C3 \\
\hline$f_{j}^{1}$ & 0.95 & 0.00 & 0.00 \\
\hline$f_{j}^{2}$ & 0.05 & 0.74 & 0.018 \\
\hline$f_{j}^{3}$ & 0.00 & 0.26 & 0.982 \\
\hline$f_{j}^{4}$ & 0.00 & 0.00 & 0.00 \\
\hline
\end{tabular}

In Table XI, the results shown in the machine shop 1 after evaluating non-dimensioning sampling values of Table VIII in the functions of each criterion.

TABLE XI. VALUES OF THE FUnCTIONS EVALUATED IN MACHINE WORKSHOP 1

\begin{tabular}{|c|l|l|l|}
\hline Criteria & C1 & C2 & C3 \\
\hline$f_{j}^{1}$ & 1.00 & 0.00 & 0.00 \\
\hline$f_{j}^{2}$ & 0.00 & 0.00 & 0.00 \\
\hline$f_{j}^{3}$ & 0.00 & 1.00 & 1.00 \\
\hline$f_{j}^{4}$ & 0.00 & 0.00 & 0.00 \\
\hline
\end{tabular}

In Table XII, the results shown in the machine shop 2 after evaluating the non-dimensioning sampling values (Table VIII) in the functions of each criterion.

TABLE XII. VALUES OF THE FunCtions EVALUATED IN MACHINE WORKSHOP 1

\begin{tabular}{|c|l|l|l|}
\hline Criteria & C1 & C2 & C3 \\
\hline$f_{j}^{1}$ & 1.00 & 0.00 & 0.00 \\
\hline$f_{j}^{2}$ & 0.00 & 0.00 & 0.00 \\
\hline$f_{j}^{3}$ & 0.00 & 0.00 & 0.46 \\
\hline$f_{j}^{4}$ & 0.00 & 1.00 & 0.54 \\
\hline
\end{tabular}

Step 4: We determine the weight of the criteria. In Table XIII, the weights of the criteria are shown; for this, (3) is used and the calculations are made for each evaluated workshop.

TABLE XIII. CRITERIA WEIGHTS FOR EACH WORKSHOP EVALUATED

\begin{tabular}{|l|l|l|l|l|}
\hline Weights & \multicolumn{1}{|c|}{$\boldsymbol{f}_{\boldsymbol{j}}^{\mathbf{1}}(\boldsymbol{x})$} & \multicolumn{1}{|c|}{$\boldsymbol{f}_{\boldsymbol{j}}^{\mathbf{2}(\boldsymbol{x})}$} & \multicolumn{1}{|c|}{$\boldsymbol{f}_{\boldsymbol{j}}^{\mathbf{3}(\boldsymbol{x})}$} & \multicolumn{1}{|c|}{$\boldsymbol{f}_{\boldsymbol{j}}^{\mathbf{4}}(\boldsymbol{x})$} \\
\hline $\mathrm{C} 1$ & 0.20 & 0.31 & 0.32 & 0.17 \\
\hline $\mathrm{C} 2$ & 0.67 & 0.43 & 0.24 & 0.08 \\
\hline $\mathrm{C} 3$ & 0.13 & 0.26 & 0.44 & 0.74 \\
\hline
\end{tabular}

Step 5: Determine the clustering coefficient. In Table XIV shows the results of the clustering coefficients, obtained through the application of (4). The shaded boxes indicate the maximum clustering value for each workshop, which indicates the level of hygienic quality it presents.

Step 6: Results using Max clustering coefficient. Table XV shows a summary with the maximum clustering coefficients that indicates the level of hygienic quality with respect to the three criteria established in the workshops.

TABLE XIV. CLUSTERING COEFFICIENT FOR EACH WORKSHOP

\begin{tabular}{|l|l|l|l|l|}
\hline & Very poor & Poor & Good & Very good \\
\cline { 2 - 5 } & $f_{j}^{1}(x)$ & $f_{j}^{2}(x)$ & $f_{j}^{3}(x)$ & $f_{j}^{4}(x)$ \\
\hline $\begin{array}{l}\text { G1: Welding } \\
\text { Workshop }\end{array}$ & 0.27 & 0.18 & 0.20 & 0.00 \\
\hline $\begin{array}{l}\text { G2: Hydraulic } \\
\text { Workshop }\end{array}$ & 0.19 & 0.34 & 0.49 & 0.00 \\
\hline $\begin{array}{l}\text { G3: Machine } \\
\text { Workshop 1 }\end{array}$ & 0.20 & 0.00 & 0.68 & 0.00 \\
\hline $\begin{array}{l}\text { G4: Machine } \\
\text { Workshop 2 }\end{array}$ & 0.20 & 0.00 & 0.20 & 0.49 \\
\hline
\end{tabular}

TABLE XV. MAXIMUM CLUSTERING COEFFICIENT FOR EACH WORKSHOP

\begin{tabular}{|l|l|l|}
\hline Group & \multicolumn{1}{|c|}{$\boldsymbol{\sigma}_{\boldsymbol{i}}^{\boldsymbol{k}}$} & Hygienic Quality Level \\
\hline G1: Welding Workshop & 0.27 & Very poor \\
\hline G2: Hydraulic Workshop & 0.49 & Poor \\
\hline G3: Machine Workshop 1 & 0.68 & Good \\
\hline G4: Machine Workshop 2 & 0.49 & Very good \\
\hline
\end{tabular}

\section{RESULTS AND DISCUSSION}

\section{A. About the Case Study}

According to the results obtained in Table XV, it can be observed that the quality level of hygiene of machine shop 2 is very good; likewise, machine shop 1 and hydraulic shop present a good level of quality and the welding workshop presents a very bad level of hygienic quality with respect to the established parameters.

In Table XVI, the analysis of each workshop is made with its respective criteria (noise, illumination, and vibration). It can be observed that in the 4 workshops with respect to the noise level they are not at the recommended level, that is, they do not comply with the minimum standards according to RM 3752008 TR.

In the present paper, the Grey Clustering methodology was used, which showed that the four workshops analyzed have a very poor level of noise quality, giving us an overview to visualize the risk in the areas. On the other side, in the study realized by Xingsong, $\mathrm{W}$ et al [11], noise measurements were taken and questionnaires were conducted to assess the psychological impact and effects of noise on workers, which showed that workers are exposed to noise in excess of $85 \mathrm{~dB}$.

TABLE XVI. RESULTS OF EACH WORKSHOP WITH THEIR RESPECTIVE CRITERIA

\begin{tabular}{|l|l|l|l|}
\hline Group & Noise & Illumination & Vibration \\
\hline $\begin{array}{l}\text { G1: Welding } \\
\text { Workshop }\end{array}$ & Very poor & Good & Poor \\
\hline $\begin{array}{l}\text { G2: Hydraulic } \\
\text { Workshop }\end{array}$ & Very poor & Poor & Good \\
\hline $\begin{array}{l}\text { G3: Machine } \\
\text { Workshop 1 }\end{array}$ & Very poor & Good & Very Good \\
\hline $\begin{array}{l}\text { G4: Machine } \\
\text { Workshop 2 }\end{array}$ & Very poor & Very Good & Very Good \\
\hline
\end{tabular}


In the study conducted by Machado, $\mathrm{M}$ et al [13], a methodology was applied to evaluate the risk of lighting in the workshops of an oil area where there was evidence of low lighting levels, as in this study, the hydraulic workshop presented the same situation. The methodology of the mentioned study mentioned with the methodology applied in our study is different in that only the physical agent of illumination can be evaluated, it does not apply for more criteria of integral risk evaluation as in the case of Grey Clustering.

In the study [15], vibration was measured for vibrating tools of 4 companies in the metal-mechanical sector, it was found that 15 of them did not exceed the permissible limits. For this study four workshops of a heavy machinery company were analyzed, finding the quality levels of each one of them, in which a workshop with a bad quality level was found; instead, the mentioned study focused only on those tools that presented a high vibration level for each company, which would have been better to apply the Grey Clustering method to obtain an integral vibration risk in each one of them.

\section{B. About the Methodology}

The Grey Clustering methodology helped us to determine the deficient points of the criteria present in each Workshop as well as the level of quality of comfort in these workshops. It is observed in Table XVII the advantages and disadvantages in the Delphi, AHP methods and FAHP [23].

TABLE XVII. AdVAntages and Disadvantages of Existing Methods FOR APPLICATION IN DIFFERENT STUDIES

\begin{tabular}{|l|l|l|}
\hline Method & Advantage & Disadvantages \\
\hline Grey clustering & $\begin{array}{l}\text { - Evaluate problems with } \\
\text { small groups of criteria. } \\
\text { • Objective } \\
\text { - Analyze with limited } \\
\text { information and uncertainty. }\end{array}$ & $\begin{array}{l}\text { - Does not cover } \\
\text { complex problems. }\end{array}$ \\
\hline DELPHI & $\begin{array}{l}\text { - Expert group estimates } \\
\text { based on experience. } \\
\text { - Application in any field } \\
\text { whether political, legal, } \\
\text { educational }\end{array}$ & $\begin{array}{l}\text { - It is subjective } \\
\text {-Appearance of bias in } \\
\text { the participants } \\
\text { (specialists) }\end{array}$ \\
\hline $\begin{array}{l}\text { AHP Intuitive } \\
\text { analytical } \\
\text { hierarchy }\end{array}$ & $\begin{array}{l}\text { - Evaluate complex problems } \\
\text { with multicriteria. }\end{array}$ & $\begin{array}{l}\text { - It requires the } \\
\text { participation of the } \\
\text { knowledge and } \\
\text { experiences of the } \\
\text { experts who will make } \\
\text { decisions about the } \\
\text { problem }\end{array}$ \\
\hline FAHP & $\begin{array}{l}\text { - Evaluate various problems } \\
\text { with multicriteria }\end{array}$ & $\begin{array}{l}\text { - It must have precise } \\
\text { and well-defined } \\
\text { information, that is, it } \\
\text { is based on fuzzy logic. }\end{array}$ \\
\hline
\end{tabular}

\section{Control Proposals}

1) Group G1: Welding workshop: Noise (Very poor quality level): As the main measure, it is proposed to realize an engineering control based on wave interference by installing equipment that eliminates the sound pressure level by more than 30 decibels, while the project is being developed it is recommended to provide the workers with personal protection equipment. Vibration (Poor quality level): It is proposed to implement anti-vibration handles for manual tools, in addition to reduce the exposure time of the workers through staff rotation and providing anti-vibration handles (as shown in Fig. 5).
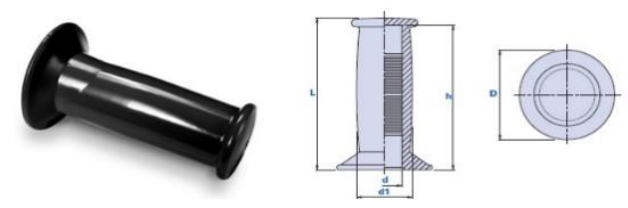

Fig. 5. Anti-Vibration Handle.

2) Group G2: Hydraulic Workshop: Noise (Very poorquality level): It is proposed to offer double hearing protection (earmuff + earplug) to workers in order to reduce exposure to noise in the work environment. Illumination (Bad Quality Level): It is proposed as an engineering control measure to redesign the illumination system to reduce the risk level of illumination and to comply with the minimum standards required in the workshop (see Fig. 6).

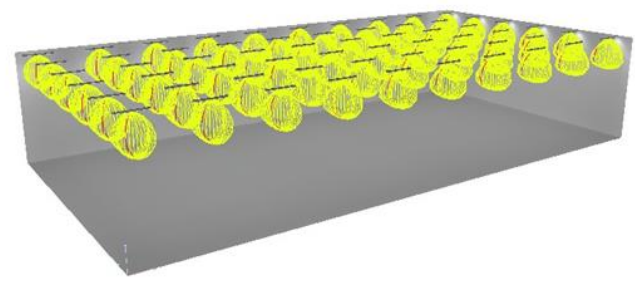

Fig. 6. Luminaire Distribution Reference.

3) Group G3: Machine workshop 1: Noise (Very poor quality level): It is proposed to provide double hearing protection (earmuff + earplug) according to the model shown in Fig. 7, to the workers in order to reduce exposure to noise in the work environment.

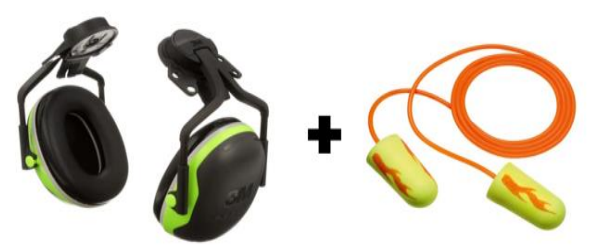

Fig. 7. Model of Recommended Earmuffs (PELTOR X4P5E- 3M) and Earplugs (3M E-A-Rsoft Yellow Neons).

4) Group G4: Machine workshop 2: Noise (Very poorquality level): It is proposed to provide double hearing protection (earmuff + earplug) according to the model shown in Fig. 7 to the workers to reduce exposure to noise in the work environment.

\section{CONCLUSIONS}

In the present work it was found that, of the 4 industrial workshops analyzed, Machine Shop 2 represents a Very Good hygienic quality level, Hydraulics and Machine Shop 1 a Good quality level, while the welding workshop represents a Very Poor-quality level. It was also observed that, in the Hydraulics 
workshop, the lighting criterion represents a Poor-quality level, in the welding workshop the vibration criterion represents a Poor-quality level, and finally for the noise criterion all areas represent a Very Poor quality level. The results obtained made it possible to propose control measures aimed at improving working conditions in the company.

The grey clustering methodology was applied, which has proved to be effective because it allowed obtaining the results of the hygienic risk in a global way and also in a specific way of the areas for each criterion that was established. This allows us to improve the management of occupational hygiene in the companies allowing to establish control measures before the risk found to reduce it to a level of better hygienic quality and improve the health of the workers, for this study this method is more effective compared to the DELPHI, AHP and FAHP methods; therefore, it is effective for the risk analysis defining groups and criteria.

In future research, it is recommended to apply the Grey Clustering method to obtain a global risk of hygienic quality in sectors such as mining, hydrocarbons, construction, and manufacturing, among others, thus continuing to improve working conditions and obtain healthy working environments. This method could also be applied to verify that the Industrial Hygiene and Safety programs are being developed effectively, otherwise further improvements will need to be implemented.

REFERENCES

[1] F. H. Robert, "Higiene industrial," Encicl. Salud y Segur. en el Trab., p. $38,2000$.

[2] D. Julong and Y. Lin, "Introduction to grey systems theory," Underst. Complex Syst., vol. 68, pp. 1-24, 1988, doi: 10.1007/978-3-642-16158$2 \_1$.

[3] A. Delgado, P. Montellanos, and J. Llave, "Air quality level assessment in Lima city using the grey clustering method," Jan. 2019, doi: 10.1109/ICA-ACCA.2018.8609699.

[4] A. Delgado and I. Romero, "Environmental conflict analysis on a hydrocarbon exploration project using the Shannon entropy," in Proceedings of the 2017 Electronic Congress, E-CON UNI 2017, 2018, vol. 2018-Janua, doi: 10.1109/ECON.2017.8247309.

[5] A. Delgado, J. Culqui, G. Tasayco, A. Millán, E. Tirado, and C. Carbajal, "Quality assessment of surface water associated with a copper mine in peruusinggrey systems," Int. J. Adv. Trends Comput. Sci. Eng., vol. 9, no. 4, pp. 6660-6668, 2020, doi: 10.30534/ijatcse/2020/359942020.

[6] L. N. Zhang, F. P. Wu, and P. Jia, "Grey Evaluation Model Based on Reformative Triangular Whitenization Weight Function and Its Application in Water Rights Allocation System," Open Cybern. Syst. J., vol. 7, no. 1, pp. 1-10, 2013.

[7] Ling P. Ling and xin W. Zheng, "An optimized grey cluster model for evaluating quality of labor force," J. Softw., vol. 8, no. 10, pp. 24892494, 2013, doi: 10.4304/jsw.8.10.2489-2494.

[8] A. Delgado, E. Luna, M. Hernández, K. Montero, and C. Carbajal, "Assessment of the air quality in four cities with near mining activity in mexico, using the grey clustering method," Int. J. Recent Technol. Eng., vol. 8, no. 3, pp. 7514-7518, Sep. 2019, doi: 10.35940/ijrte.C5696.098319.

[9] A. Delgado, J. Maguiña, R. Cabezas, S. Hidalgo, and C. Carbajal, "Integral assessment of risk level in libraries using the grey clustering method," Int. J. Recent Technol. Eng., vol. 8, no. 3, 2019, doi: 10.35940/ijrte.C5695.098319.

[10] A. Delgado and I. Romero, "Social impact assessment on a hydrocarbon proyect using triangular whitenization weight functions," 2016, doi: 10.1109/CACIDI.2016.7785998.

[11] X. Wang, O. A. Orelaja, D. S. Ibrahim, and S. M. Ogbonna, "Evaluation of noise risk level and its consequences on technical operators of tobacco processing equipment in a cigarette producing company in Nigeria," Sci. African, vol. 8, p. e00344, 2020, doi: 10.1016/j.sciaf.2020.e00344.

[12] B. Z. González, V. P. Sierra, J. I. V. Martínez, Y. C. Muraira, and V. R. Catalina, "Disminución Auditiva de Trabajadores Expuestos a Ruido en una empresa Metalmecánica," Ciência Trab., vol. 35, no. April 2016, pp. 233-236, 2010.

[13] E. T. Machado Miranda, S. E. Nuela Sevilla, A. P. López-López, and D. L. Mosquera Guanoluisa, "Evaluación niveles de iluminación en interiores y cálculo para instalaciones de alumbrado," KnE Eng., vol. 2020, pp. 13-36, 2020, doi: 10.18502/keg.v5i2.6215.

[14] M. E. Abdullah, M. A. Hassan, and A. Israr, "Vibration response of human arm in machine operation," 6th Int. Conf. Aerosp. Sci. Eng. ICASE 2019, 2019, doi: 10.1109/ICASE48783.2019.9059121.

[15] C. Arias, J., Martínez, "Evaluación de la exposición al riesgo por vibraciones en el segmento mano brazo en compañías del sector metalmecánico,” Med. Segur. Trab. (Madr)., vol. 62, no. 245, pp. $327-$ 336, 2016.

[16] A. Delgado, A. Aguirre, E. Palomino, and G. Salazar, "Applying triangular whitenization weight functions to assess water quality of main affluents of Rimac river," Proc. 2017 Electron. Congr. E-CON UNI 2017, vol. 2018-Janua, pp. 1-4, 2018, doi: 10.1109/ECON.2017.8247308.

[17] V. Bax, W. Francesconi, and A. Delgado, "Land-use conflicts between biodiversity conservation and extractive industries in the Peruvian Andes," J. Environ. Manage., vol. 232, pp. 1028-1036, Feb. 2019, doi: 10.1016/j.jenvman.2018.12.016.

[18] L. Sifeng and L. Yi, Grey Systems, Theory and Applications. Chennai; India: Springer, 2010.

[19] S. Liu and Y. Lin, "Grey Information:Theory and Practical Applications," New York, 2006.

[20] S. Liu and Y. Lin, Grey Systems: Theory and Applications. Berlin: Springer, 2010.

[21] R. M. N. 375-2008-TR, "Norma Básica de Ergonomía y de Procedimiento de Evaluación de Riesgo Disergonómico," pp. 1-17, 2008.

[22] M. J. Griffin, "Vibraciones," Encicl. Salud Y Segur. En El Trab. en la OIT, vol. II, p. 18, 2012.

[23] A. Delgado and H. Flor, "Selection of the best air purifier system to urban houses using AHP," in 2017 CHILEAN Conference on Electrical, Electronics Engineering, Information and Communication Technologies, CHILECON 2017 - Proceedings, 2017, vol. 2017-Janua, doi: 10.1109/DISTRA.2017.8229622. 